
государственный политехнический университет (НПИ) им. М. И. Платова", e-mail:rrevunov@mail.ru

ЧУМАКОВА ВИКТОРИЯ НИКОЛАЕВНА

к.т.н., доцент Новочеркасского инженерно-мелиоративный институт им. А. К. Кортунова - филиала ФБГБОУ ВО "Донской государственный аграрный университет"; ФОГБОУ ВО "Южнополитехнический университет (НПИ) им. М. И. Платова", e-mail: Vchumakova1980@mail.ru

ЯНЧЕНКО ЕЛЕНА АНАТОЛЬЕВНА

к.т.н., доиент ФГБНУ " проблем мелиорации " ФГБОУ ВО "Южно-Р оссийский государственный политехнический университет (НПИ) им. М. И. Платова", e-mail: Yn70@mail.ru

\title{
КАЧЕСТВО ВОАНЫХ РЕСУРСОВ БАССЕЙНА АОНА КАК ФАКТОР ЭКОНОМИЧЕСКОГО РАЗВИТИЯ РЕГИОНОВ ЮГА РОССИИ
}

Аннотауия. Цель работы заключается в том, чтобы идентифицировать показатели качественного состояния водных ресурсов в бассейне Дона, определить ареаль максимальной водохозяйственной депрессии, обосновать организационно-экономические инструменты повышения эколого-экономической эффективности системы управления бассейновым водопользованием. Использование в процессе исследования методов статистической обработки массивов данных, структурирования и группировки, способов научной абстракции, моделирования социально-экономических тендениий региона позволило идентифицировать основные атрибутивные признаки водопользования в бассейне реки Дон на современном этапе. Качество водных ресурсов на различных участках бассейна реки Дон детерминировано хозяйственной активностью водопользователей. Низкая эффективность применяемых технологий водоочистки приводит к эмиссии загрязняющих вещееств в донскую акваторию в ареалах крупнейших промышленно-хозяйственных агломераций, в частности г. Воронежа, Ростова-на-Дону. Кроме того, одним из факторов, определяющих загрязнение водных ресурсов Дона, является использование сельскохозяйственными товаропроизводителями отрасли растениеводства ядохимикатов и удобрений, которые вместе с поливной водой поступают в почву и затем через подземные

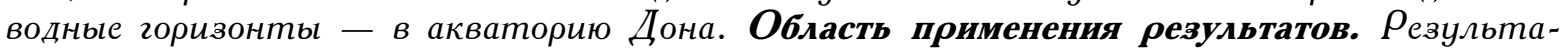
ты исследования могут быть использованы органами государственной власти Южного

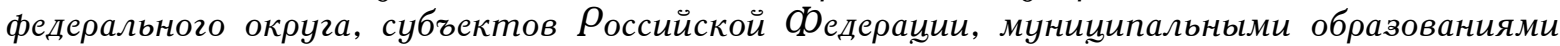
при составлении планов экономического развития отраслей региональной экономики, разработке стратегий и программ развития, а также хозяйствующиии субъектами, осуществляющими производственную деятельность, связанную с использованием водных ресурсов. На основе анализа современного состояния бассейна сформулируем основные проблемы бассейна Дона: ухудшающееся вследствие загрязнения экологическое состояние водных объектов; дефицит водоресурсных благ надлежащего качества; трансграничная эмиссия сточных вод. Авторами обосновывается механизм межведомственной координации, направленный на повышение эффективности современной системы управления водопользованием.

КАючевые слова: река Дон, водные ресурсы, водопользование, региональная экономика. 
NOVOSELSKAYA LYUBOV ANATOLEVNA

master of the "South-Russian state

Polytechnic University (NPI). M. I. Platov",

e-mail: lanovoselskaya2019@mail.ru

\begin{abstract}
REVUNOV ROMAN VADIMOVICH

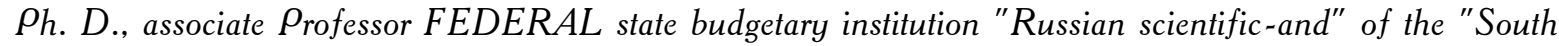

-Russian

state Polytechnic University (NPI). M. I. Platov",

e-mail:rrevunov@mail.ru
\end{abstract}

CHUMAKOVA VICTORIA NIKOLAEVNA

candidate of technical Sciences, $\rho_{\text {rofessor Novocherkassk engineering-meliorative Institute }}$ they. A. K. kortunova - branch of the DON state agrarian UNIVERSITY

University"; of the "South-Russian state

Polytechnic University (NPI). M. I. Platov", e-mail:Vchumakova1980@mail.ru

YANCHENKO ELENA ANATOL YEVNA

Ph. D., associate $P_{\text {rofessor, Russian research Institute }}$ problems of land reclamation" of the "South-Russian state

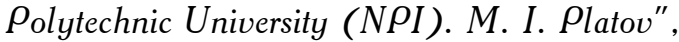
e-mail:Yn70@mail.ru

\title{
QUALITY OF WATER RESOURCES OF THE DON BASIN AS A FACTOR OF ECONOMIC DEVELOPMENT OF REGIONS OF THE SOUTH OF RUSSIA
}

Abstract. The purpose of the work is to identify indicators of the quality of water resources in the don basin, to determine the areas of maximum water depression, to justify the organizational and economic tools to improve the ecological and economic efficiency of the basin water management system. The use of methods of statistical processing of data sets, structuring and grouping, methods of scientific abstraction, modeling of socio-economic trends in the region allowed to identify the main attributes of water use in the don river basin at the present stage. The quality of water resources in different parts of the don river basin is determined by the economic activity of water users. Low efficiency of water treatment technologies leads to the emission of pollutants into the don water area in the areas of the largest industrial and economic agglomerations, in particular, Voronezh, Rostov-on-don. In addition, one of the factors determining the pollution of the water resources of the don is the use of pesticides and fertilizers by agricultural producers of the crop industry, which, together with irrigation water, enter the soil and then, through underground water horizons - into the waters of the don. The scope of the results. The results of the study can be used by the public authorities of the southern Federal district, the subjects of the Russian Federation, municipalities in the preparation of plans for the economic development of the regional economy, the development of strategies and programs, as well as economic entities engaged in production activities related to the use of water resources. Based on the analysis of the current state of the basin, we will formulate the main problems of the don basin: the environmental condition of water bodies deteriorating due to pollution; the shortage of water resources of good quality; transboundary emission of wastewater. The authors substantiate the mechanism of interdepartmental coordination aimed at improving the efficiency of modern water management system.

Keywords: don river, water resources, water use, regional economy.

Введение. Несбалансированная водохозяйственная практика на микро- и мезоэкономическом уровнях, приводящая к перманентному загрязнению акваторий водных объектов, провоцирует негативные социо-эколого-экономические последствия в виде ухудшения доступа к водоресурсным благам надлежащего качества. Дефицит водных ресурсов ограничивает экономическое развитие и сспособствует росту социальной напряженности. В связи с этим не вызы- 
вает сомнений актуальность и научно-практическая значимость исследований, направленных на поиск направлений интенсификации практики водопользования РФ в контексте снижения антропогенного воздействия на акватории водных объектов. С учетом сказанного исследуем качественные характеристики водных ресурсов в бассейне реки Дон.

Методология исследования. Для обобщенной оценки качества воды реки Дон и ее притоков по выделенным водным объектам и речным участкам используется удельный комбинаторный индекс загрязненности воды (УКИЗВ), позволяющий учесть как степень превышения стандартов качества воды отдельными загрязняющими веществами, так и частоту подобных превышений в границах периода наблюдения. По результатам расчета УКИЗВ $[7,8,9]$ сформулируем следующие выводы:

- вниз по течению Дона от фонового створа до Цимлянского водохранилища воды относились преимущественно к классу «слабозагрязненные» или «загрязненные» (УКИЗВ от 2,0 до $3,9)$; при этом в створах ниже г. Воронежа, Лиски и Калач-на-Дону качество воды ухудшалось до уровня «грязных вод» (класс 4 разряд «а») (УКИЗВ от 4 до 5,9);

- в пределах участка «Цимлянское водохранилище - устье» качество донской воды по сравнению с вышерасположенным участком заметно ухудшилось: в большинстве створов наблюдений показатели речной воды превысили уровень «загрязненных вод» (УКИЗВ >3);

- в нижнем течении Дона худшим качеством по совокупности показателей отличался участок «Цимлянское водохранилище - поселок Багаевский» (в большинстве створов здесь значение УКИЗВ выше 4,0, т. е. выше нижней границы класса «грязных вод»); наиболее загрязненным является участок реки ниже впадения реки Северский Донец;

- качество воды притоков первого порядка по значениям УКИЗВ варьировалось в широких пределах: «слабо загрязненные» воды характерны для р. Красивая Меча и Сосна; «загрязненные» - Азовский оросительный канал; «очень загрязненные» - Девица, Воронеж, Битюг, Богучар; «грязные» (4 класс разряд «а») - Чир, «грязные» (4 класс разряд «б») - Северский Донец, Сал, Маныч; «экстремально грязные» - Темерник;

- на участке реки Дон до Цимлянского водохранилища фактически определяющими значение комплексной оценки качества воды были загрязняющие вещества: железо, органические вещества, медь; в некоторых створах ниже крупных населенных пунктов - нитриты;

- на участке реки Дон от Цимлянского водохранилища до устья фактически определяющими значение комплексной оценки качества воды были следующие загрязняющие вещества: в Цимлянском водохранилище и далее до впадения реки Северский Донец - марганец, алюминий, нефтепродукты, медь; ниже впадения р. Северский Донец - медь, сульфаты, нитриты, нефтепродукты; ниже г. Ростова-на-Дону - медь, сульфаты, нефтепродукты, нитриты, фенолы;

- в устьевой части наиболее загрязненных притоков определяющими значение комплексной оценки качества воды являлись следующие загрязняющие вещества: в р. Чир - марганец, нефтепродукты; в реке Северский Донец - алюминий, сульфаты, марганец, железо, медь; в реке Сал - алюминий, марганец, сульфаты, медь, железо; в р. Маныч - алюминий, сульфаты, марганец, медь, железо, магний; в р. Темерник - алюминий, марганец, азот аммонийный, нитриты.

Рассматривая качество воды в р. Дон по совокупности загрязняющих веществ $[15,16,17]$, к наиболее загрязненным его участкам можно отнести: участок ниже г. Воронежа (нарушение качества воды по нитритам, меди, железу, аммонийному азоту, свинцу, фосфатам, цинку, нефтепродуктам); ниже г. Лиски (нарушение качества воды по свинцу, меди, нитритам, железу, нефтепродуктам, фосфору фосфатов, аммонийному азоту); в районе г. Калач-на-Дону (нарушение качества воды по марганцу, нефтепродуктам, меди, железу, нитритам, фосфору фосфатов, сульфатам); участок от впадения р. Северский Донец до г. Аксая (алюминий, марганец, медь, сульфаты, нефтепродукты, железо); ниже г. Ростова-на-Дону (медь, сульфаты, нефтепродукты, нитриты, фенолы). Показатели качества водных ресурсов на различных участках бассейна Дона за период 2017-2018 годов представлены в таблице $1[18,19]$. 
НОВОСЕЛЬСКАЯ Л.А., РЕВУНОВ Р.В., ЧУМАКОВА В.Н., ЯНЧЕНК Е.А.

Качество водных ресурсов на различных участках бассейна Дона за период 2017-2018 годов

\begin{tabular}{|c|c|c|c|}
\hline Границы водохозяйственного участка & $\begin{array}{c}\text { Основные вещества- } \\
\text { загрязнители, поступаю- } \\
\text { щие в акваторию }\end{array}$ & $\begin{array}{c}\text { Приоритетные водопользова- } \\
\text { тели-загрязнители }\end{array}$ & $\begin{array}{c}\text { Удельный ком- } \\
\text { бинаторный ин- } \\
\text { декс загрязнен- } \\
\text { ности воды }\end{array}$ \\
\hline $\begin{array}{l}\text { p. Дон, граница Тульской и Липецкой } \\
\text { областей — граница Липецкой и Во- } \\
\text { ронежской областей }\end{array}$ & Органические вещества & $\begin{array}{l}\text { МП «Водоканал» г. Лебе- } \\
\text { дянь; хозяйствующие субъек- } \\
\text { ты агропромышленного ком- } \\
\text { плекса }\end{array}$ & $5,1-5,5$ \\
\hline $\begin{array}{l}\text { p. Дон, граница Липецкой и Воронеж- } \\
\text { ской областей - г. Лиски }\end{array}$ & $\begin{array}{l}\text { Железо, сточные воды, } \\
\text { фосфаты }\end{array}$ & МП ПУ «Воронежводоканал» & $5,3-5,7$ \\
\hline $\begin{array}{l}\text { p. Дон, выше впадения р. Северский } \\
\text { Донец - ниже х. Колузаево }\end{array}$ & Медь & $\begin{array}{l}\text { Хозяйствующие субъекты } \\
\text { промышленного комплекса }\end{array}$ & $2,5-2,7$ \\
\hline р. Дон, г. Лиски - выше г. Богучар & Нитриты, железо & $\begin{array}{l}\text { Аксайский филиал ФГУ } \\
\text { «Ростовмеливодхоз», ОАО } \\
\text { «ПО Водоканал» (г. Ростов- } \\
\text { на-Дону) }\end{array}$ & $2,2-2,9$ \\
\hline $\begin{array}{l}\text { Ростовская агломерация - ниже впа- } \\
\text { дения р. Темерник }\end{array}$ & $\begin{array}{l}\text { Нитриты, железо, поверх- } \\
\text { ностноактивные вещества, } \\
\text { сточные воды }\end{array}$ & $\begin{array}{l}\text { ОАО «ПО Водоканал» (г. } \\
\text { Ростов-на-Дону) }\end{array}$ & $4,7-5,9$ \\
\hline Выше г. Богучар — г. Калач-на-Дону & Марганец, нитраты & $\begin{array}{l}\text { Хозяйствующие субъекты } \\
\text { промышленного комплекса }\end{array}$ & $4,3-5,5$ \\
\hline $\begin{array}{l}\text { г. Калач-на-Дону — Цимлянское во- } \\
\text { дохранилище }\end{array}$ & Марганец, нитраты & $\begin{array}{l}\text { Хозяйствующие субъекты } \\
\text { промышленного комплекса }\end{array}$ & $4,4-5,5$ \\
\hline
\end{tabular}

По результатам выполненных исследований приведена интегральная оценка экологического состояния бассейна Дона на основе комплексной оценки качества воды с характеристикой вклада отдельных показателей в формирование УКИЗВ. На основании анализа средних (медианных) концентраций загрязняющих веществ, рассчитанных в замыкающих створах водохозяйственных участков и максимальных концентраций, полученных при моделировании содержания загрязняющих веществ в максимально загрязненной струе при расчетных неблагоприятных гидрологических условиях внутри водохозяйственных участков, можно заключить следующее. Качество водных ресурсов на различных участках бассейна реки Дон детерминировано хозяйственной активностью водопользователей. Низкая эффективность применяемых технологий водоочистки приводит к эмиссии загрязняющих веществ в донскую акваторию в ареалах крупнейших промышленно-хозяйственных агломераций, в частности г. Воронежа, Ростова-на-Дону. Кроме того, одним из факторов, определяющих загрязнение водных ресурсов Дона, является использование сельскохозяйственными товаропроизводителями отрасли растениеводства ядохимикатов и удобрений, которые вместе с поливной водой поступают в почву и затем через подземные водные горизонты - в акваторию Дона $[4,6]$.

Развитая транспортно-логистическая инфраструктура Ростовской области, обеспечивающая не только региональные потребности, но и внешнеторговый оборот Российской Федерации, обусловливает дополнительную техногенно-антропогенную нагрузку на донскую акваторию. Значительное загрязнение р. Дон нефтепродуктами характерно начиная от участка в черте г. Ростова-на-Дону и далее до устья реки - в местах территориальной локализации объектов портовой инфраструктуры $[10,12]$.

Поскольку, по данным моделирования влияния сбросов сточных вод на качество речной воды, повышение концентраций не обнаружено (в сточных водах марганец не контролируется), можно предполагать наличие на этих участках в контролируемых или неконтролируемых источниках высокого содержания данного металла.

К числу наиболее характерных видов негативного воздействия вод в бассейне $\mathrm{p}$. Дон относятся: затопление населенных пунктов, промышленных объектов, сельскохозяйственных уго- 
дий половодьями и паводками, а также в результате возникновения аварий на гидротехнических сооружениях (ГТС); обрушение берегов.

Количественной оценкой негативного воздействия вод, обусловленного затоплением освоенных территорий, является величина ущерба. Основной причиной возникновения ущербов от затопления является вовлечение в хозяйственный оборот пойменных, периодически затапливаемых территорий. На Нижнем Дону половодье 1994 году обеспеченностью 5 \% (максимальный расход в нижний бьеф Цимлянского гидроузла - 3360 м3/с, суммарный максимальный расход по створу ст. Раздорской - 4100-4200 м3/с) вызвало затопление поймы на площади около 213 тыс. га и нанесло материальный ущерб около 22 млрд руб. в ценах 1994 года $[5,14]$. В результате высокого половодья были затоплены населенные пункты, животноводческие фермы, полевые станы, жилые и хозяйственные постройки, разрушены естественные и искусственные покрытия дорожных дамб, уничтожены посевы. Столь значительная величина ущерба во многом определялась тем, что после ввода в эксплуатацию Цимлянского гидроузла нижнедонская пойма рассматривалась и осваивалась как потенциально незатапливаемая территория, при ее освоении не учитывалась возможность прохождения половодий аналогичных половодью 1994 года.

Особый характер имеют затопления освоенных территорий, обусловленные возникновением аварийных ситуаций на гидротехнических сооружениях. Основными причинами возникновения аварийных ситуаций на гидротехнических сооружениях являются $[1,2,3]$ : их неудовлетворительное техническое состояние; плохая организация службы эксплуатации сооружений, а иногда и ее полное отсутствие. Это обусловлено тем, что водохозяйственный комплекс бассейна испытывает дефицит средств на содержание, развитие и безопасную эксплуатацию ГТС; объемы реконструкции и капитального ремонта отстают от темпов старения основных фондов. В неудовлетворительном состоянии в бассейне находится более тысячи ГТС поднадзорных Минприроды России и более двух с половиной тысяч ГТС, находящихся в муниципальной собственности или не имеющих собственника, причем, как показывают результаты обследований состояния ГТС, выполненные в последние годы по ряду областей в бассейне Дона, приведенные выше цифры явно занижены в несколько раз.

В бассейне р. Дон широко развиты процессы негативного воздействия вод, обусловленные переработкой берегов водохранилищ и рек. В качестве наиболее показательных, как по масштабам проявления, так и по размерам причиненного ущерба, рассматриваются последствия переработки берегов Цимлянского водохранилища и нижнего Дона на участке от створа Цимлянского гидроузла до г. Ростова-на-Дону (в районе расположения населенных пунктов и объектов социально-экономического значения).

С целью выявления водных объектов и освоенных в их бассейнах территорий, подверженных затоплению, а также определения на этой основе очередности выполнения системы мероприятий, обеспечивающих снижение ущербов, возникающих при затоплении освоенных территорий, необходимо выполнить районирование территории бассейна по степени паводковой опасности [13]. Оценка степени паводковой опасности территорий основывается на концепции риска ущербов от наводнений, определяемого как произведение риска паводков и суммарной величины ущерба, возникающего при затоплении освоенных территорий.

Результаты. Подводя итог сказанному, сформулируем основные выводы:

1. Качество водных ресурсов бассейна Дона существенно различается, колеблясь, в соответствии с расчетными значениями удельного комбинаторного индекса загрязненности воды, в диапазоне от умеренно загрязненной до очень грязной. Подобная дифференциация обусловлена неравномерностью развития отраслей экономики в ареале водосборного бассейна. При этом, в силу естественных природных причин, вещества-загрязнители распространяются вместе с донской водой на значительные расстояния от ареала загрязнения.

2. Для регионов Донского водосборного бассейна характерен дефицит водоресурсных благ надлежащего экологического качества [11]. Указанная тенденция провоцирует дополнительные издержки хозяйствующих субъектов, связанных с решением проблемы обеспечения водой производственного процесса. Это, в свою очередь, снижает показатели экономической эффективности и увеличивает период окупаемости инвестиционных проектов. В итоге дефицит водоресурсных благ ограничивает конкурентоспособность товаропроизводителей Юга 
России.

3. Дополнительными факторами ухудшения качественных характеристик водных ресурсов Дона и связанным с данным процессом ростом издержек хозяйствующих субъектов являются эмиссия сточных вод с территории Украины (через реку Северский Донец, являющуюся притоком Дона), а также наличие в Ростовской области развитой транспортно-логистической инфраструктуры, обеспечивающей как региональный, так и общероссийский внутренний и внешний торговый оборот, что приводит к значительному загрязнению Дона нефтепродуктами в районе Ростовского порта.

4. По нашему мнению, решение задачи улучшения качества водных ресурсов в бассейне Дона, в целях снижения негативных социо-эколого-экономических последствий современного водопользования, возможно посредством формирования механизма координации организационно-управленческих действий федеральных органов власти (в лице профильных ведомств: Министерства природных ресурсов, Федерального агентства водных ресурсов, Донского бассейнового водного управления), органов госвласти субъектов РФ, органов местного самоуправления. Предлагаемая координация позволит устранить существующее в настоящее время распыление ограниченных финансовых, материальных ресурсов между водоохранными проектами разной степени важности.

5. Практическое воплощение предлагаемого выше механизма межведомственной координации может выражаться в виде формируемого ежегодно и утверждаемого Правительством РФ единого бассейнового водоохранного бюджета, в котором предусматривается финансирование заранее отобранных экспертами приоритетных водосберегающих проектов, обладающих максимальным социо-эколого-экономическим эффектом. Реализация подобного предложения позволит концентрировать ресурсы на наиболее перспективных направлениях, дающих наибольший практический результат.

Выводы. В заключение на основе анализа современного состояния бассейна сформулируем основные проблемы бассейна Дона: ухудшающееся вследствие загрязнения экологическое состояние водных объектов; дефицит водоресурсных благ надлежащего качества; трансграничная эмиссия сточных вод. Авторами обосновывается механизм межведомственной координации, направленный на повышение эффективности современной системы управления водопользованием.

Лuтература

1. Абраменко И. П. Направления эколого-экономической оптимизачии использования водньх ресурсов региона (на примере Ростовской области) / Абраменко И. П., Абраменко П. И., Новосельская Л. А., Саркисян А.Р. // Экономика и предпринимательство. - 2018. - № 10(99). - С. 368-371.

2. Абраменко И. П. Эколого-экономические приоритеты развития водопользования на мезоэкономическом уровне (на материалах Ростовской области) / Абраменко И. П., Новосельская Л. А., Саркисян А. Р., Янченко Е. А. // Экономика и предпринимательство. - 2018. - № 10 (99). - С. 308-310.

3. Анопченко Т. Ю. Управление рисками инвестиционно-строительных проектов развития урбанизированных территорий / Анопченко Т. Ю., Мурзин А. Д. // Монография. Ростов-на-Дону, 2012.

4. Губачев В. А. Природохозяйственные императивы аграрного производства на мезоэкономическом уровне: инструменты и алгоритмы повышения эффективности / Губачев В. А. // Конкурентоспособность в глобальном мире: экономика, наука, технологии. - 2017. - № 10 (57). - С. 189-194.

5. Дальченко Е. А. Приоритетные механизмы интенсификации использования ресурсного потенцииала региона в контексте реализации его конкурентных преимуществ (на материалах Ростовской области) / Дальченко Е. А., Чумакова В. Н. // Конкурентоспособность в глобальном мире: экономика, наука, технологии. - 2017. - № 4-3 (39). - С. 65-68.

6. Мурзин А. Д. Идентификация и диагностика эколого-экономических рисков урбанизированньх территорий / Мурзин А. Д.// Российский академический журнал. - 2009. - T. 9. - № 4. - С. 38-41.

7. Офиџиальный сайт Донского бассейнового водного управления. [Электронный ресурс]. Режим достуna: http://www.donbvu.ru/water_situation/(дата обращения 9 апреля 2019 г.), свободный. — Загл. с экрана. 8. Офищиальный сайт Министерства природных ресурсов РФ. [Электронный ресурс]. Режим доступа: http://mnr.gov.ru (дата обращения 31 марта 2019 г.), свободный. - Загл. с экрана.

9. Официальный сайт Федерального агентства водных ресурсов. [Электронный ресурс]. Режим достуna: http://voda.mnr.gov.ru (дата обращения 9 апреля 2019 г.), свободный. - Загл. с экрана.

10. Плохотникова Г. В. Инструменты стимулирования сочиально-экономического развития региона (на материалах Ростовской области) / Плохотникова Г. В., Дальченко Е. А., Чумакова В. Н. // Экономика и предпринимательство. - 2018. - № 5 (94). - С. 1256-1259.

11. Ревунов Р. В. Направления модернизации механизма управления природопользованием на региональном уровне / Ревунов Р. В., Ревунов С. В. // Региональная экономика. Юг России, 2018. - № 3(21). [Электронный ресурс]. Режсим доступа: https://doi.org/10.15688/re.volsu.2018.3.17, свободньй. — Загл. с экрана. 
12. Ревунов Р. В. Организационно-экономические и нормативно-правовые аспекты повышения эффективности системы управления водопользованием на мезо- и микроэкономическом уровнях / Ревунов Р. B. // Водоочистка. - 2016. - № 4. - C. 41-46.

13. Ревунов С. В. Инструменты повышения эффективности природопользования на микро- и мезоэкономическом уровнях / Ревунов С. В., Янченко Д. В. // Конкурентоспособность в глобальном мире: экономика, наука, технологии. - 2017. - № 3-1 (32). - С. 145-147.

14. Чумакова В. Н. Водохозяйственная практика региона: направления модернизаичи и повышения эффективности / Чумакова В. Н., Новосельская Л. А., Янченко Д. В. // Экономика и предпринимательство. - 2018. - № 9 (98). - С. 1288-1290.

15. Экологический вестник Дона «О состоянии окружающей среды и природных ресурсов Ростовской области в 2017 г.», Ростов-на-Дону, 2018.

16. Экологический вестник Дона «О состоянии окружающей среды и природных ресурсов Ростовской области в 2016 г.», Ростов-на-Дону, 2017.

17. Экологический вестник Дона «О состоянии окружающей среды и природных ресурсов Ростовской области в 2015 г.», Ростов-на-Дону, 2016.

18. Экологический вестник Дона «О состоянии окружающей среды и природных ресурсов Ростовской области в 2014 г.», Ростов-на-Дону, 2015.

19. Экологический вестник Дона «О состоянии окружающей среды и природных ресурсов Ростовской области в 2013 г.», Ростов-на-Дону, 2014.

\section{References:}

1. Abramenko I. P. Napravleniya ehkologo-ehkonomicheskoj optimizacii ispolzovaniya vodnyh resursov regiona (na primere Rostovskoj oblasti) / Abramenko I. P., Abramenko P. I., Novoselskaya L. A., Sarkisyan A.R. // Ehkonomika i predprinimatelstvo. 2018. No. 10(99). S. 368-371.

2. Abramenko I. P. Ehkologo-ehkonomicheskie prioritety razvitiya vodopolzovaniya na mezoehkonomicheskom urovne (na materialah Rostovskoj oblasti) / Abramenko I. P., Novoselskaya L. A., Sarkisyan A. R., Yanchenko E. A. //Ehkonomika i predprinimatelstvo. 2018. No. 10 (99). S. 308-310.

3. Anopchenko T. Yu. Upravlenie riskami investicionno-stroitel'nyh proektov razvitiya urbanizirovannyh territorij / Anopchenko T. Yu., Murzin A. D. // Monografiya. Rostov-na-Donu, 2012.

4. Gubachev V. A. Prirodohozyajstvennye imperativy agrarnogo proizvod-stva na mezoehkonomicheskom urovne: instrumenty $i$ algoritmy povysheniya ehffektivnosti / Gubachev V.A. // Konkurentosposobnost v global'nom mire: ehkonomika, nauka, tekhnologii. 2017. No. 10 (57). S. 189-194.

5. Dalchenko E. A. Prioritetnye mekhanizmy intensifikacii ispolzovaniya resursnogo potenciala regiona $v$ kontekste realizacii ego konkurentnyh preimushchestv (na materialah Rostovskoj oblasti) / Dal'chenko E. A., Chumakova V. N. // Konkurentosposobnost v globalnom mire: ehkonomika, nauka, tekhnologii. 2017. No. 4-3 (39). S. 65-68.

6. Murzin A. D. Identifikaciya i diagnostika ehkologo-ehkonomicheskih riskov urbanizirovannyh territorij / Murzin A. D.// Rossijskij akademicheskij zhurnal. 2009. T. 9. No. 4. S. 38-41.

7. Oficialnyj sajt Donskogo bassejnovogo vodnogo upravleniya. [An electronic resource]. Access mode: http:// www.donbvu.ru/water situation/ (data obrashcheniya 9 aprelya 2019 g.), free. Heading from the screen.

8. Oficialnyj sajt Ministerstva prirodnyh resursov RF. [An electronic resource]. Access mode: http://mnr.gov.ru (data obrashcheniya 31 marta $2019 \mathrm{~g}$.), free. Heading from the screen.

9. Oficialnyj sajt Federalnogo agentstva vodnyh resursov. [An electronic resource]. Access mode: http:// voda.mnr.gov.ru (data obrashcheniya 9 aprelya 2019 g.), free. Heading from the screen.

10. Plohotnikova $G$. V. Instrumenty stimulirovaniya socialno-ehkonomicheskogo razvitiya regiona (na materialah Rostovskoj oblasti) / Plohotnikova G. V., Dalchenko E. A., Chumakova V. N. // Ehkonomika i predprinimatel'stvo. 2018. No. 5 (94). S. 1256-1259.

11. Revunov R. V. Napravleniya modernizacii mekhanizma upravleniya prirodopolzovaniem na regionalnom urovne / Revunov R. V., Revunov S. V. // Regionalnaya ehkonomika. Yug Rossii, 2018. No. 3(21). [An electronic resource]. Access mode: https://doi.org/10.15688/re.volsu.2018.3.17, free. Heading from the screen.

12. Revunov R. V. Organizacionno-ehkonomicheskie i normativno-pravovye aspekty povysheniya ehffektivnosti sistemy upravleniya vodopolzovaniem na mezo- $i$ mikroehkonomicheskom urovnyah / Revunov R. V. // Vodoochistka. 2016. No. 4. S. 41-46.

13. Revunov $S$. V. Instrumenty povysheniya ehffektivnosti prirodopolzovaniya na mikro-i mezoehkonomicheskom urovnyah / Revunov S. V., Yanchenko D. V. // Konkurentosposobnost v globalnom mire: ehkonomika, nauka, tekhnolo-gii. 2017. No. 3-1 (32). S. 145-147.

14. Chumakova V. N. Vodohozyajstvennaya praktika regiona: napravleniya modernizacii i povysheniya ehffektivnosti / Chumakova V. N., Novoselskaya L. A., Yanchenko D. V. // Ehkonomika i predprinimatelstvo. 2018. No. 9 (98). S. $1288-1290$.

15. Ehkologicheskij vestnik Dona «O sostoyanii okruzhayushchej sredy i pri-rodnyh resursov Rostovskoj oblasti v 2017 g.», Rostov-na-Donu, 2018.

16. Ehkologicheskij vestnik Dona «O sostoyanii okruzhayushchej sredy i pri-rodnyh resursov Rostovskoj oblasti v 2016 g.», Rostov-na-Donu, 2017.

17. Ehkologicheskij vestnik Dona "O sostoyanii okruzhayushchej sredy i pri-rodnyh resursov Rostovskoj oblasti v 2015 g.», Rostov-na-Donu, 2016.

18. Ehkologicheskij vestnik Dona «O sostoyanii okruzhayushchej sredy i pri-rodnyh resursov Rostovskoj oblasti v 2014 g.», Rostov-na-Donu, 2015.

19. Ehkologicheskij vestnik Dona «O sostoyanii okruzhayushchej sredy i pri-rodnyh resursov Rostovskoj oblasti v 2013 g.», Rostov-na-Donu, 2014. 